\title{
From the Postwar to the Nineties: Culture and Profession in Corporate Periodicals in Italy
}

\author{
Silvano Tozzo* \\ Politecnico di Milano, Piazza Leonardo da Vinci, 32 - 20133 Milan, Italy \\ *Corresponding author: Silvano Tozzo,, Piazza Leonardo da Vinci, 32 - 20133 Milan, Italy, Tel: +0039 23497504366 ; E-mail: \\ silvano.tozzo@polimi.it
}

Received date: November 14, 2014, Accepted date: January 27, 2015, Published date: February 07, 2015

Copyright: $\odot 2015$ Tozzo S. This is an open-access article distributed under the terms of the Creative Commons Attribution License, which permits unrestricted use, distribution, and reproduction in any medium, provided the original author and source are credited.

\begin{abstract}
A survey on periodicals published by companies and professional associations. The partial review analyses the context from which the journals come out and how this reflects the evolution of the productive sector in Italy. The editorial circumstances related to the periodicals and organisational processes within companies and associations are assembled for a better understanding of aims behind the commitment to corporate publishing.
\end{abstract}

Keywords: Publishing; Periodicals; Companies; Postwar; Culture

\section{Introduction}

The volumes of the Italian statistical yearbook (ASI) from the 1960s each devote an entire page with tables reporting the contemporary situation of the periodical press within Italy ${ }^{1}$. The figures contained in the general summary are of two types, frequency of issue and general topic. The growth in the number of periodicals from the 1950s to the 1960s is significant, with 4870 titles being published in 1955 compared to 7380 by 1966.

During the same time, the layout of the tables in the yearbook introduce some variations in how the cultural and scientific areas are listed, which in turn changes the classification of individual classes, but for the purpose of an appropriate reading the effect is minimal when it comes to identifying the evolution of arguments over time. The grouping Science and technology contained 1812 titles in 1957 (compared to the total number of periodicals of 4941), while just five years later, the 1962 yearbook reports that 2041 of 5489 titles were devoted to the same class. The four top-level categories ${ }^{2}$ used in the first 1960s containing the individual classes leaving room for the new schematic reorganisation in the years that followed [1-5].

The data reflecting the periodical press in 1966, published in the 1969 yearbook, introduces new categories in its classification of periodicals, including to the new one of Company journals, shown last in the table. The criteria used to qualify this last class are not clearly defined $^{3}$, but the data from 1966 are significant when compared to the general scheme. The 170 company titles published in that year are identified as a discrete segment in absolute terms and in comparison with other groupings ${ }^{4}$, probably also signalling the growth of the industrial sector in the 1960 s.

\section{Periodical Press}

The publications considered here are representative of periodicals edited, published or supported by companies, organisations and public or private associations. Some of these such as Civilization of machines (Civiltà delle macchine) which first appeared in 1953, had a discrete appeal during the postwar years due to their overall philosophy and the context in which they arose. Others such as Technical geology (Geologia tecnica) appeared in the 1960s as important blends of cultural transmission and the consolidation of professional categories such as the Italian geologists as they gradually organised their profession.

Among the periodicals examined here, Highways (Autostrade) is the one whose contents and language significantly reflect its operational and cultural background. This is reflected by the fact that the "Society concessions and constructions highways spa" began publishing the journal in 1959, a few years after its establishment and the concomitant task of construction of the Highway Milan-Naples

$1 \quad$ It might seem excessive to highlight the space devoted to the figures on the periodical press but one only needs to look at a yearbook from the 1980s to see the difference in terms of published data and space allocated to them; it has been cut from an entire page to just a few lines with the essential figures.

2 The volume came out in 1961 with data for 1960 in general (but for 1957 concerning the periodical press) organizes the first-level categories as follows:1. Arts and literature 2. Science and technology 3. Information and documentation and finally a fourth class identified as "Miscellaneous". The classification used in the 1969 yearbook (for the 1966 data about periodicals) use topics not grouped as in the earlier volumes.

3 The category "corporate journals" can be interpreted as periodicals of enterprise content with issues that concern companies but not necessarily published by the manufacturing sector. But it is also possible a reading of publishing and promotional character connected to companies and therefore as a direct product of one or more associated enterprises. Probably the category includes both.

4 The 170 titles classified in 1966 are positioned rather well when compared with several other classes. For example, there are 131 periodicals in "teaching and education", 41 on "commerce, communications and transport", 120 on "geography and travel". While other topics are quite large, such as 1,465 in "political science and economics:" and 413 in "medicine and hygiene". 
(Highway of the sun). The periodical started publication after “...the organisation's various publications underwent subsequent transformations as we realised that information was needed not only for internal use but also to keep out leaders and all external collaborators updated on the latest technological innovations". 5

That period was characterised by legislative action ${ }^{6}$ that eventually led to the expansion and improvement of the road and motorway networks across the country. The Highways company wold play a prominent role in the construction of the new high speed roads as well as the maintenance of the existing highway system ${ }^{7}$. The articles in the journal document the evolution of the highway building sector and the role the Company played in the development of infrastructure, providing a history of different construction and highway maintenance projects over the years as well as a general portrait of the development of the Italian highway system.

In effect, the purpose of Highways was expressly underscored in the introduction to its 10th anniversary issue, which stated that the journal was to be" a faithful reflection of the work being done by the Society". 8 This commemorative issue, besides reviewing the entire evolution of the Company, also provides insights into its organisational affiliations and its legal position. In addition to being part of Association of Italian concessionaires societies of highways and tunnels (Associazione Italiana Società Concessionarie Autostrade e Trafori AISCAT) ${ }^{9}$, the organisation for motorway concession companies, the Highways Society is also within the influence of the IRI. Article I of the by-laws of the Institute for Industrial Reconstruction (Istituto per la Ricostruzione Industriale) as approved in 1948 state that the IRI is a financial institution under public law with headquarters in Rome. The IRI manages the investments and assets owned by it."

The IRI was established in 1933 to provide technical and financial support to the industrial sector and over time would assume responsibility for reorganising and expanding parts of the country's manufacturing sector. In the mid-1950s, the organisational structure of the IRI consisted primarily of five societies ${ }^{10}$ that had been gradually formed since the 1930s, to which it had delegated various functions to allow the companies within the IRI to be more effectively managed. It was during this time that the main IRI companies began to pay more attention to aspects such as communication, press and cultural initiatives [6-10].

The structures used for this purpose were enhanced to fulfill a policy of supporting "... the services of public relations and company newspapers, putting pressure on financial corporations and individual companies to make them stronger and, where they did not exist, to establish them". ${ }^{11}$

The strategy promoting the creation of effective communication tools sought to provide information and cultural understandings as well a better perception of the company's philosophy both internally and externally. As the IRI began issuing corporate journals, they had "28 titles at the beginning of the 1960s, most published on a monthly basis with publication runs between 1,000 and 50,000 copies" ${ }^{12}$

It was in this context that Civilization of machines first hit the presses, albeit at a level higher than other publications whose language and contents were less theoretical and more practical in orientation. At the intersection of different topical emphases, the journal offered a highly-qualified cultural commentary with articles by intellectuals in various disciplines, including philosophers, engineers, writers, architects and artists who were seeking to bring into conversation areas of knowledge once considered far apart. In what was most likely a unique publishing experiment, at least for the 1950s, when the first issue of Civilization of machines opened with an article ${ }^{13}$ analysing the situation of the Italian mechanical industry. In effect, the publisher of reference is Finmeccanica (Finance mechanics society), a company founded in 1948 because of the difficult situation facing the machinebuilding industry in the aftermath of the war [11-15].

The act creating Finmeccanica ${ }^{14}$ Finmeccanica and specifies the tasks assigned to the new entity relating to the reorganisation of the machine-building sector. By the 1980s, the introduction to an anthology dedicated to Civilization of machines gave a good synthesis of Finmeccanica's purpose: "Finmeccanica was first of all an aggregation point for dozens of companies devastated by the war and then the port of arrival or transit for many other companies involved in the process of reconversion or renovation". ${ }^{15}$ These few lines effectively describe Finmeccanica's path after the war, when the difficult economic circumstances required a considerable effort on important part of machine-building sector.

The journal Advanced Technologies (Tecnologie d'avanguardia) has its origins in a later chapter in Finmeccanica history. The ACNP Italian catalogue of periodicals ascribes the journal's birth the late 1970s when the new objectives the IRI subsidiary had adopted in the 1960s needed to be consolidated as "the Management Board decided that the group should concentrate on three areas: automotive, aerospace and energy". ${ }^{16}$

Indeed, the automotive sector was in the midst of a crisis due to the accumulation of negative factors such as the oil shortages of the 1970s

5 Highways (1969), 8, Rome, Highways society, p 3

6 Law n. 463/1955 - Interministerial decree of October 15, 1955 - Law 729/1961

7 It seems useful to remember that the construction of the first highways (in Italy) dates back to the 1920s, following an intense debate on the opportunity to give the automotive sector higher-speed alternatives separate from the ordinary road system. The Milan-Lakes highway was the first mass project inaugurated in 1924.

8 The August 1969 is dedicated to the journal's tenth anniversary; the excerpt here appeared on page 4.

9 Association of Italian concessionaires societies of highways and tunnels

10 STET, FINMARE, FINSIDER, FINMECCANICA, FINELETTRICA

11 Amatori F.(2013), The economic miracle and the role of IRI 1949-1972, : Laterza,,p. 343.

12 Amatori F.(2013), The economic miracle and the role of IRI 1949-1972, : Laterza,p. 342.

13 Saraceno P.(1953), The Italian mechanical industry, "Civilization of machines", 1, p. 8-11.

14 Legislative Decree 1420 of December 15, 1947.

15 Scheiwiller V.(1989), Civilization of machines. Anthology of a journal 1953-1957, Milan:Finmeccanica, preface.

16 Felice E, (2009), Public Sector and profitability.The ascent of Finmeccanica, in: 5.the weapons of the republic from the liberation to today, Turin:UTET, p.305. 
that eventually led to the industry being divested in 1986. The company's energy segment also found itself with financial problems as the country reconsidered its approach to the use of nuclear energy and the subsequent closure of the plants built by Ansaldo, a Finmeccanica subsidiary. Meanwhile, the aeronautical sector at Finmeccanica followed a different trajectory as it gradually became more important once AerItalia was founded " to strengthen industrial structures significantly and provide a more incisive Italian presence on the international market".

Some of the development strategies planned by the leaders of Finmeccanica are express ${ }^{17}$ Finmeccanica uses the journal to present its different levels of operations, strategic sectors and the comprehensive range of functions carried out by the Group. In effect, research into advanced technological processes is compared across the volumes by analysing the impact on the reality of the moment and the company's commitment in terms of organization and research ${ }^{18}$.

Volume 10, $1983^{19}$ is devoted to research and the entire configuration of the sector; its introduction expressly states: "The purpose of this publication is therefore twofold: a) to provide an overview of the capabilities of research and testing at Finmeccanica group; and b) to provide a consultative tool for those companies that intend to avail themselves of the group's research and development services". ${ }^{20}$

The value of point $b$ is further enhanced as the introduction goes on to affirm that "we attach great importance to this last objective because it, in fact, represents a specific, diffused and continuous way through which the Group can concretely work to improve the quality and therefore of the competitiveness of small and medium manufacturing companies". ${ }^{21}$

The setting of the volume is reflected by how the four sectors into which the company was divided are presented with their structures through detailed information sheets about their activities, tools and identifying those industrial segments that might be potentially affected [16-20].

Everything was then summarized at the end of the issue with an integrated schematic that crosses centres and specific functions to present the overall structure of the available technological services

The two journals by Finmeccanica are emblematic of their position within the periodical press. Civiltà delle macchine took on an experimental attitude in a period full of great expectations solicited by expanding technology and well documented in Sinisgalli's journal. Advanced Technologies, as the group's true manifesto, was an effective instrument for presenting the company, but also a way to disseminate information about the evolution of specific technological sectors ${ }^{22}$.
With different roots not properly corporate, Technical Geology (Geologia tecnica) also falls within the category of manifesto publications, albeit in this case that of a professional association. The journal was created in 1967 by the merger of two previous journals that derived from the circle of geologists. The reasons behind the founding of the new periodical were numerous, including the desire "to meet the needs of geologists and other technicians, especially engineers, who need to be informed about the issues in the practice of geology". Ardito Desio wrote this in the first issue of the journal, recalling the pressure by the ANGI, the Italian geologists' association, for which the journal was the official organ from 1967 to 1970.

In this first phase of its existence, the journal's content was articulated by a discreet number of topics such as "original technicalscientific and informative articles, press releases, legal texts and regulations relating to geology and geologists, news about refresher and training courses, reports on international conferences, bibliographical news, debates and proposals on reforms to the degree courses in geological sciences, and, finally, the official statements of ANGI and from 1969 the National Board of Geologists". ${ }^{23}$ In addition to disseminating technical and scientific information, the journal also became a source of news about the many initiatives.

In 1970, the journal transitioned for various reasons from being the official organ of ANGI to an independent publication, only to be followed the failure of the publisher and other events which affected the professional associations of Italian geologists. After a period where the journal did not appear, Technical Geology resumed publication under a new editor and became the official organ of the ONG, the National Board of Geologists.

The ONG was created in 1963 by Article 8 of Act $112^{24}$. Article 9 of the same law specifies its purpose as including the promotion of "compliance with the professional law and any other provisions relating to the profession", in effect creating a national register of geologists and specifying in Article 3 those skills that a geologist should possess.

The ONG's support of the journal became significant given what was happening in Italy during the 1960s and 70sas a result of hydrogeological instability. In the editorial of the first issue of 1971, the new editor does not fail to underscore that the journal "has been and will continue to be not only an informative instrument for the profession, but will also be an effective instrument for spreading an awareness of geological issues within the country." it is not difficult to translate the director's affirmation in a desiderable more attention from the institutions towards preventing natural calamities and protecting the country's territory.

17 Advanced technologies. 4 The space tomorrow, 1980, p 6.

18 From the introduction of volume 10/1983 of Advanced technologies “....The Finmeccanica group in its quality as great industrial operator of our country, has developed and continually enhanced and boosted a large and articulated internal structure of research and experimentation..."

19 Advanced technologies 10 The organization of research in the Finmeccanica group, Rome,1983.

20 Advanced technologies 10 The organization of research in the Finmeccanica group, p. 3.

21 Advanced technologies 10 The organization of research in the Finmeccanica group, introduction.

22 In this regard it is interesting, for example, the volume 8 (1982), which, through four chapters and numerous images, It reveals the evolution of the airplane engine from the beginnings to the early eighties.

23 Introduction to Index of published writings on Technical geology from 1967 to 1970, Technical geology,1,1971, p.5.

24 Article 8, National Board of Geologists, "The affiliate to the Albo constitute the National Board of Geologists and they elect the national council of the Board" 
This brief survey of corporate and professional association periodicals related to the manufacturing sector will close with some comments on the economic area, in this case, the two categories of publishers listed as Agencies of commerce and Banks.

It is interesting to note how the insertion of the two terms "Agencies" and "Commerce" into the Author field of the national bibliographic database, it produces a surprising number of results covering a wide range of topics. The introduction of a temporal restriction to focus on the decades immediately following the Second World War resizes certainly the outcome of the bibliographic research but still returns significant numerical results ${ }^{25}$.

It is evident how the publishing promotion, even in the recent past, was a sensible voice within the functions carried out by Agencies of commerce. A text published in the early sixties reports explicity "And finally, the vast publishing activity of the agencies:... almost all of the agencies print their official bulletins, which often assume the character of real economic journals, full of news and information, then there is the whole production of other publications, periodicals or not, on the most important aspects of local and national economic life". ${ }^{26}$ The periodical Economic Chronicles (Cronache economiche) reenters into this category. Published by the Turin Agency of Commerce "it plays a prominent role until 1986 as an instrument of information, debate and study of all the problems in Turin's and the national economy". ${ }^{27}$ The journal includes essential articles connected with the evolution of the Agencies of commerce as a whole in relation to the transformations in the organisational structure of the system. The functions related to the network of companies and the regional economy helped to verify the situation of the moment and the critical elements of the productive sector.

Even the journal promoted by Cariplo (now Intesa Bank), in a wider dimension, contemplate thematics related to the company's segment in financial and market analysis.

Among publications by banking institutions, the Milan Journal of economy (Rivista Milanese di economia) invokes some of the classic attributes of the sector, including outward appearance, graphic design, the aesthetic quality of the issues, all of which are peculiar to the books and periodicals published by the banks. Created in the early eighties through its columns it gives space to arguments of different nature maintaining the economic sphere as principal topic of the journal. In effects the presence of qualified articles of historical and sociological character makes breach into the economic theme treated in ample way in its various shades.

In the 80 s, the journal reports on the return "quarterly publication out commerce", thus maintaining that exclusivity so typical of the editorial production of the Banks. Factor, the latter criticized on different occasions in the writings on the subject because of the evident difficulty in finding works of elevated documentary standard.

Some authors identify this distributive controlled policy with motivations unrelated to those of the classic publishing industry, reasons probably connected to prestige and self-promotion. In any case the reasons behind banks' financial commitment to culture are summarised with statements such as "the need for tax relief, the reinvestment of net profits..., the desire to nurture one's own image, a genuine cultural impulse". ${ }^{28}$

Already in the early twentieth century, financial institutions had begun to pay more attention to publishing. But it was only after the Second World War that the sector started to assume a more marked connotation, in fact "after 1960, the publishing activity of banks loses its spontaneity and becomes constant... It begins to become a coherent cultural policy in the sector that in the 70s will morph into corporate strategy". ${ }^{29}$ The journals in this context play a significant role in carving out an important space that by the 1990s would consist of a hundred titles "....the most important group is constituted by technical-economic journals with a consolidated scientific prestige that express originality of contributions and derive from the studies sector within the company...".30

The titles discussed here shed more light on the corporate press, a publishing segment probably less known because of its less commercial focus, the specificity of its contents and limited and controlled distribution. Given the limited nature of this survey, the argument has certainly not been exhausted, but can instead become an initial reflection leading to a more systematic and wide-ranging approach.

\section{References}

1. Saraceno P (1953) The Italian mechanical industry, Civilization of machines 1: 8-11.

2. Saraceno P (1953) The Italian mechanical industry, Civilizations of machines 1: 8-11.

3. Unioncamere (1961) The agencies of commerce in the first centenary of the unification of Italy, Giuffrè, Milan, Italy.

4. Unioncamere (1961) The agencies of commerce in the first centenary of the unification of Italy, Giuffre, Milan, Italy.

5. Scheiwiller V (1989) Civilization of machines. Anthology of a Journal 1953-1957,Finmeccanica. Scheiwiller, Milan, Italy.

6. Scheiwiller V (1989) Civilization of machines; Anthology of a Journal 1953-1957. Scheiwiller, Milan, Italy.

7. Agency of commerce (1992) The Agency of Commerce of Turin across the time, Turin

8. Agency of Commerce (1992) The Agency of Commerce of Turin across the time. Turin.

9. Schettini Piazza E (1995) The Publishing Banking in Italy. Publishing history of Europe, Shakespeare and Company Futura. Florence 5: 405-416.

10. Schettini Piazza E (1995) The Publishing Banking in Italy, Publishing. history of Europe, Shakespeare and Company Futura. Florence 5: 405-416.

11. Eco U (1995) A treasure disinterred. Publishing history of Europe, Shakespeare and Company Futura. Florence 8: 399-404.

12. Eco U (1995) A treasure disinterred. Publishing history of Europe, Shakespeare and Company Futura. Florence 8: 399-404.

13. Chahinian R (1998) The system of the agencies of commerce. The corporate management of the Agency of commerce. Cedam,Padova 11: 23-37.

\footnotetext{
25 Over 2600 results which become almost 700 in the time interval 1946/1979

26 Unioncamere (1961) The agencies of commerce in the first centenary of the unification of Italy, :Giuffrè, p. 59

27 Agency of commerce (1992), The Agency of Commerce of Turin across the time, , p. 6

28 Schettini Piazza E.(1995), The Publishing Banking in Italy, in; Publishing history of Europe, : Shakespeare \& Company Futura, p. 405.

29 Schettini Piazza E (1995), The Publishing Banking in Italy, in; Publishing history of Europe, : Shakespeare \& Company Futura, p. 410.

30 Schettini Piazza E. (1995), The Publishing Banking in Italy, in; Publishing history of Europe, :Shakespeare \& Company Futura, p. 412.
} 
Citation: Tozzo S (2015) From the Postwar to the Nineties: Culture and Profession in Corporate Periodicals in Italy. Arts Social Sci J 6: 94 . doi: $10.4172 / 2151-6200.100094$

Page 5 of 5

14. Chahinian R (1998) The system of the agencies of commerce, Cedam Padova 11: 23-37.

15. Felice E (2009) Public Sector and profitability. The ascent of Finmeccanica. 5. the weapons of the republic from the liberation to today UTET. Turin 12: 294-319.

16. Finmeccanica.. (1958) The Finmeccanica group, Finmeccanica propaganda office, Roma, Italy.

17. Da Rios G (2010) The first highways. Seven thousand years of streets, Edicem, Milano, Italy.
18. Amatori F (2013) The economic miracle and the role of IRI 1949-1972, Laterza, Bari.

19. National Council of geologists (2013) The first 50 years of the Professional Italian Board of Geologists: almanac through history, curiosity and chronicle, part one 1963/1982, CNG, Rome.

20. National Council of Geologists (2013) The first 50 years of the professional Italian Board of geologists: Almanac through history, curiosity and chronicle. part two 1983/2013. 